JTTEE5 22:10-17

DOI: 10.1007/s11666-012-9847-x

1059-9630/\$19.00 ㄷ ASM International

\title{
Liquid-Solid Self-Lubricated Coatings
}

\author{
S. Armada, R. Schmid, S. Equey, I. Fagoaga, and N. Espallargas
}

(Submitted May 6, 2012; in revised form October 3, 2012)

\begin{abstract}
Self-lubricated coatings have been a major topic of interest in thermal spray in the last decades. Self-lubricated coatings obtained by thermal spray are exclusively based on solid lubricants (PTFE, h-BN, graphite, $\mathbf{M o S}_{2}$, etc.) embedded in the matrix. Production of thermal spray coatings containing liquid lubricants has not yet been achieved because of the complexity of keeping a liquid in a solid matrix during the spraying process. In the present article, the first liquid-solid self-lubricating thermal spray coatings are presented. The coatings are produced by inserting lubricant-filled capsules inside a polymeric matrix. The goal of the coating is to release lubricant to the system when needed. The first produced coatings consisted solely of capsules for confirming the feasibility of the process. For obtaining such a coating, the liquid-filled capsules were injected in the thermal spray flame without any other feedstock material. Once the concept and the idea were proven, a polymer was co-sprayed together with the capsules to obtain a coating containing the lubricant-filled capsules distributed in the solid polymeric matrix. The coatings and the self-lubricated properties have been investigated by means of optical microscopy, Scanning Electron Microscopy, and tribological tests.
\end{abstract}

Keywords flame spraying, friction reduction, liquid-solid coatings, lubricant release, self-healing, selflubricated coatings

\section{Introduction}

The University of Illinois (USA) performed the first demonstration of an autonomic (without manual intervention) self-healing material in 2001. This first autonomic selfhealing material was a paint obtained by preparing an epoxy matrix composite reinforced with $10 \%$ of microcapsules filled with healing agent and $2.5 \%$ catalyst. In this invention, the healing agent was released when a crack was formed in the material and hit the capsule with the purpose of healing the damage and restoring the initial properties of the coating (Ref 1). Later on, just one decade ago, a wide range of selfhealing polymer-based materials or approaches have been developed in paints, using the same principle (Ref 2-6).

Self-healing materials were initially designed for recovering the initial properties of the material containing the healing agent. However, healing the whole system (coating/material integrity and functionality) is important in many applications for enlarging the service life of components. Even after restoring the material properties while keeping the operational properties of the system, there still remains a gap to be covered by self-healing materials, although a big effort and advances are

S. Armada, R. Schmid and S. Equey, SINTEF, Materials and Chemistry, Trondheim, Norway; I. Fagoaga, Tecnalia, Irun, Spain; and N. Espallargas, Tribology Lab, Department of Engineering Design and Materials, Faculty of Engineering Science and Technology, Norwegian University of Science and Technology, NTNU, 7491 Trondheim, Norway. Contact e-mail: sergio.armada@sintef.no. encountered in corrosion applications where corrosion inhibitors are used as healing agents (Ref 4-6).

So far, most self-healing coatings have been developed for use as paints. The main limitation of paints is their limited mechanical properties. Therefore, the paints are not an optimal technology for high demanding mechanical components in machine elements. The scope of this study is to produce a new generation of thermally sprayed self-healing coatings containing nano and/or microcapsules filled with a liquid lubricant. The proposed coatings have better mechanical properties than paints; thus, an important and new field of application for such proposed coatings are machine elements (e.g., bearings, hydraulic systems, etc.) where maintaining low wear rates and full film lubrication proves to be a challenge. These coatings aim at providing machine components with a reservoir of liquid lubricant in the material that can be released when lubricant-starving conditions arise in the system. The main challenge for producing liquid-containing self-healing coatings by thermal spray is to avoid any damage to the capsules during the production process as the temperature of the flame can damage the capsule material and thus burn the liquid lubricant, which is normally oil.

Many thermal spray coating materials have been used to meet demanding conditions for protecting surfaces against wear or for tailoring the coefficients of friction of moving parts (e.g., cermet, WC- and $\mathrm{Cr}_{3} \mathrm{C}_{2}$-based, Mo, etc.) (Ref 7, 8). Their applications include critical components such as airplane's landing gears, pistons and cylinders for engines, valves, and bearings among others. In almost all these applications, lubricants are required to be used to minimize wear and friction between the moving parts. However, lubricant leakages or lubricant supply failures during operation can lead to lubricant-starving conditions, eventually resulting in failure and downtimes, and both energy and economical losses. Failures and downtimes in industrial applications require maintenance periods that can vary in length depending on the component. Maintenance operations of mechanical components are known to be risky and 
pose health and security issues for companies. Analyses of EUROSTAT databases showed that around $15-20 \%$ (depending on country) of all accidents are related to maintenance operations (Ref 9). Therefore, the proposed thermally sprayed self-lubricating coatings aim at reducing the maintenance operations and downtimes by avoiding unlubricated conditions in rotating/sliding parts by releasing the lubricating agent contained in the coatings when starving situations might occur.

In the present study, the first family of these liquid-solid self-lubricating thermal spray coatings will be presented. Nylon matrix coatings containing polymeric capsules filled with synthetic oil have been prepared by flame spray and characterized. The aim is to show the feasibility of the process.

\section{Experimental Procedure}

\subsection{Liquid-Filled Capsules Preparation}

Lubricant-filled microcapsules of polyurea (PU) were synthesized by miniemulsion polymerization. Oil-in-water miniemulsions were prepared by emulsifying an oil-phase $(20 \% \mathrm{v} / \mathrm{v})$ in an aqueous phase by means of an ultrasonifier (Labsonic 2000) in small-scale experiments, and a homogenizer (15MR-8TA, APV GAULIN Inc.) in large scale experiments. The oil-phase consisted of isophorone diisocyanate and lubricant in various ratios as shown in Table 1. The aqueous continuous phase consisted of a $10 \mathrm{~g} / \mathrm{L}$ polyvinylalcohol (Celvol 523) stabilizer solution. Guanidine carbonate $\left(\mathrm{NCO} / \mathrm{NH}_{2}\right.$ molar ratio of 1$)$ was added to this premade miniemulsion and interfacial polymerization performed at $70^{\circ} \mathrm{C}$ during $16 \mathrm{~h}$. The size and size distribution of the prepared microcapsules was determined by means of dynamic light scattering (DLS) using a LS230 Coulter Counter (Coulter Instruments).

\subsection{Thermal Spray Process}

The substrate material was ST-52 carbon steel (S355M according to EN 10113-3), which was degreased and grit

Table 1 Overview of polyurea microcapsule synthesis using various amounts and types of lubricants

\begin{tabular}{lcc}
\hline Lubricant type & $\begin{array}{c}\text { Lubricant } \\
\text { amount, vol. } \%\end{array}$ & $\begin{array}{c}\text { Capsule } \\
\text { size, } \boldsymbol{\mu m}\end{array}$ \\
\hline Polyalphaolefin(a) (PAO) & 30 & 3.4 \\
Polyalphaolefin (PAO) & 50 & 2.7 \\
Polyalphaolefin (PAO) & 70 & 2.9 \\
Silicone oil 100cs(b) & 70 & 2.4 \\
Silicone oil 1000cs(c) & 70 & 7.1
\end{tabular}

(a) Mereta 46 (Statoil). (b) Silicone oil AP 100 (FLUKA). (c) $200^{\circledR}$ Fluid 1000cs (Dow Corning) blasted using corundum grade 24 just before the spraying process. The roughness $(\mathrm{Ra})$ of the substrates was about $3 \mu \mathrm{m}$. A commercial Nylon-11 powder (ET-11 E+C Evertuff, polyamid-11 hereafter called Nylon), and the capsule suspensions were sprayed using a flame spray system with a Eutectic Terodyn 3500 gun (Eutectic Castolin). In order to confirm the viability of thermal spray process, a coating consisting only of liquid-filled capsules (without any matrix) was also obtained using standard parameters for the Nylon (see Table 2).

As the flame spray equipment does not allow introducing the capsule suspension in the feeding system, a set-up for cospraying the nylon powder and the capsules was designed. The suspension containing the capsules was fed into the flame using a feeder located close to the nozzle of the gun allowing the control of the total amount of capsules, injection angle, and position. The main objective of this system was to avoid the degradation of the capsule shell material during the spraying process and assure that the aqueous solution was completely evaporated during the thermal spray process.

\subsection{Lubricating Properties of the Coatings}

The lubricating properties of the coatings were studied using a reciprocating tribometer (Resmat, Canada). The tests consisted of measuring the Coefficient of Friction (CoF) of a 4.76-mm-diameter AISI 316 steel ball rubbing against the coatings. The test parameters are shown in Table 3. Layers containing solely capsules, pure nylon coatings, and capsule-containing coatings were tested.

The samples were studied using a Field EmissionScanning Electron Microscope (FE-SEM) Zeiss Ultra 55 (Cambridge, UK). A carbon-sputtered layer was deposited on the coating surface for achieving a better electrical conductivity and for improving the SEM images, as well as avoiding any degradation of the capsule shell due to the voltage used in the electron beam of the SEM.

\section{Results and Discussion}

\subsection{Capsule Production}

Lubricant-filled PU microcapsules were synthesized from an oil-in-water emulsion using the miniemulsion polymerization method. Miniemulsion processes are based on using premade stable emulsions in the submicron or micron range as nano and microreactors. The droplets are

Table 3 Parameters of the tribological test

\begin{tabular}{lllll}
\hline Stroke, $\mathbf{m m}$ & $\begin{array}{c}\text { Sliding speed, } \\
\mathbf{m m} / \mathbf{s}\end{array}$ & $\begin{array}{c}\text { Load, } \\
\mathbf{N}\end{array}$ & $\begin{array}{c}\text { Test length, } \\
\mathbf{m i n}\end{array}$ & $\begin{array}{c}\text { Temperature, } \\
{ }^{\circ} \mathbf{C}\end{array}$ \\
\hline 10 & 10 & $5 \& 10$ & 30 & 23 \\
\hline
\end{tabular}

Table 2 Thermal spray parameters

\begin{tabular}{lccccc}
\hline Air, psi & $\begin{array}{c}\text { Propylene, } \\
\mathbf{p s i}\end{array}$ & $\begin{array}{c}\text { Spray distance, } \\
\mathbf{m m}\end{array}$ & $\begin{array}{c}\text { Spray rate (Nylon), } \\
\mathbf{k g} / \mathbf{h}\end{array}$ & $\begin{array}{c}\text { Spray rate (capsules), } \\
\mathbf{k g} / \mathbf{h}\end{array}$ & $\begin{array}{c}\text { Number } \\
\text { of passes }\end{array}$ \\
\hline $90-120$ & $15-18$ & $150-250$ & $0.5-3$ & $0.05-0.3$ & $10-20$ \\
\hline
\end{tabular}




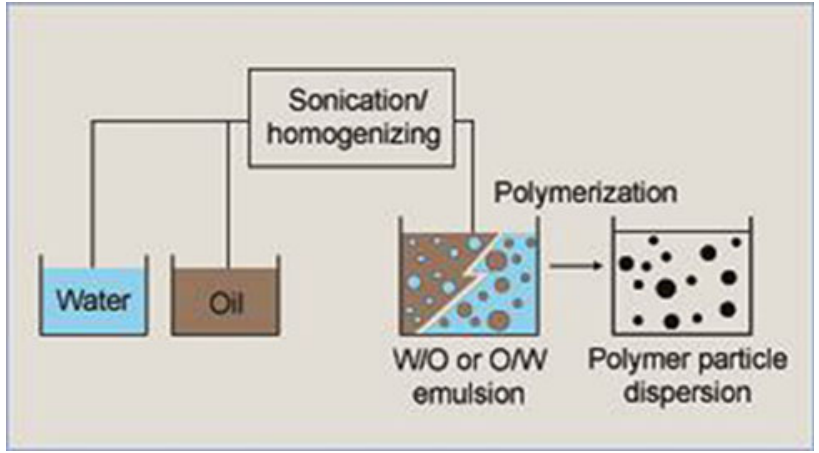

Fig. 1 Principle of miniemulsion polymerization process
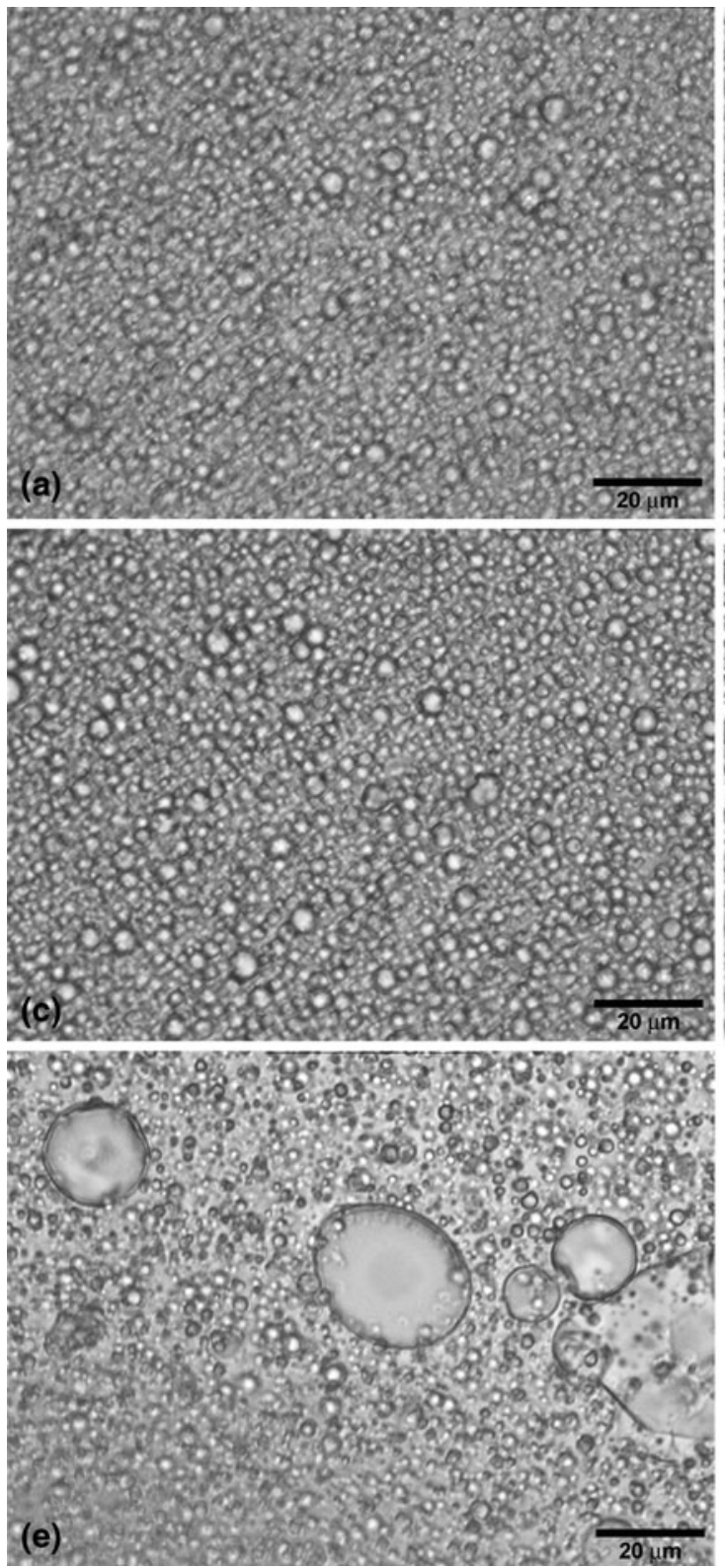

stabilized against both diffusional degradation (Ostwald ripening) and coagulation by the use of a co-stabilizer together with an efficient surfactant (Ref 10-12). In the case of this study, the liquid lubricants (Table 1) themselves could be used as co-stabilizers because of their low water-solubility. In the miniemulsion process, all ingredients in the dispersed phase (isophorone diisocyanate and lubricant) are mixed before the emulsification resulting in an emulsion with the same composition of lubricant and monomer in each droplet. These droplets function as microreactors and keep size and content almost equal to the droplet size and content of the initial emulsion, when polymerizing into microparticles (Fig. 1) (Ref 13). In this study, interfacial polymerization at the droplet interface
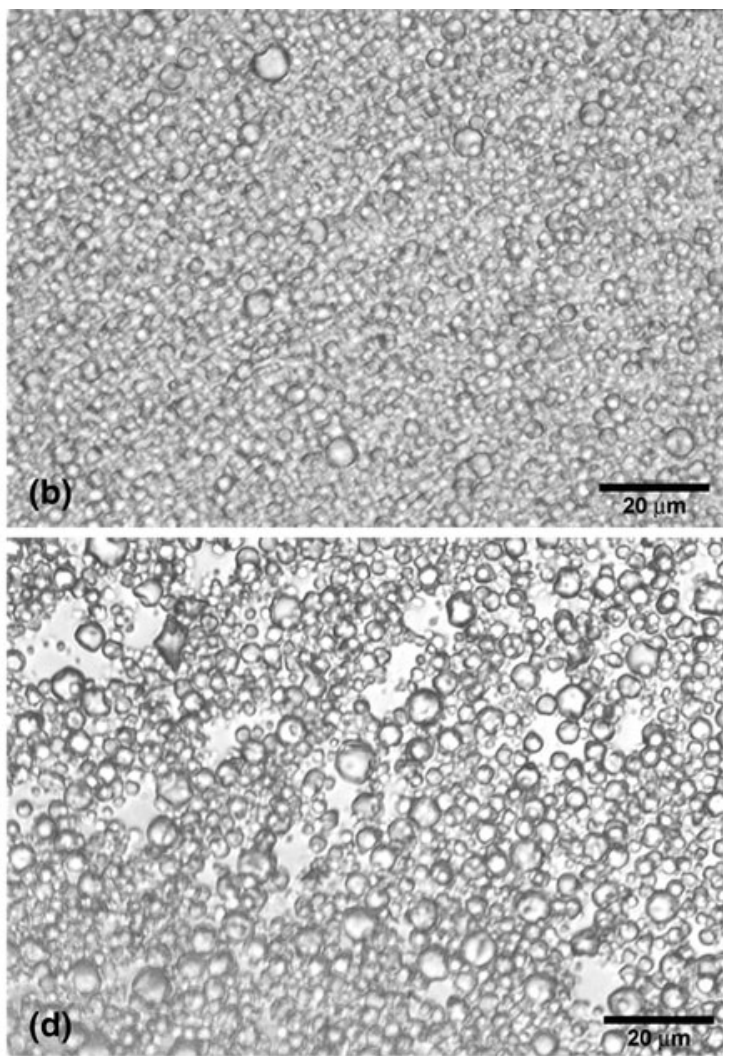

Fig. 2 Optical micrograph of aqueous dispersions of liquid-filled polyurea capsules with various types and amounts of lubricant: (a) $30 \%$ polyalphaolefin (PAO), (b) $50 \%$ PAO, (c) $70 \%$ PAO, (d) $70 \%$ Silicone oil 100cs, and (e) $70 \%$ Silicone oil 1000cs (bar in micrographs $=20 \mu \mathrm{m})$ 
was used for shell formation around the liquid core by adding one of the monomers (diisocyanate) to the lubricant droplets and the other monomer (guanidine) to the continuous phase of the premade stable emulsion.

The amount and type of lubricant were varied; an overview of the capsule synthesis is shown in Table 1. In almost all the cases, lubricant type or amount did not influence the capsule size and yield ( $>90 \%)$. The exception is for the silicone oil with the highest viscosity, where the encapsulation was incomplete (yield $\sim 70 \%$, substantial oil-phase floating on top of the aqueous dispersion) and the capsule size was remarkably larger, explained by a less-effective homogenization in high-viscosity systems. PU capsules of the size $3 \mu \mathrm{m}$, containing 30-70 vol. \% of polyalphaolefin (PAO) as liquid lubricant were used in the coating experiments. An optical micrograph of aqueous dispersions of these capsules is shown in Fig. 2.

\subsection{Coatings}

3.2.1 Spraying System. The thermal spray parameters were selected based on the characteristics of the feedstock material used as a matrix for producing the coatings. Therefore, the selected spraying parameters of the sam-

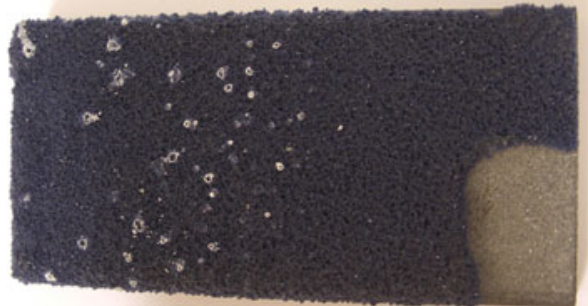

(a)

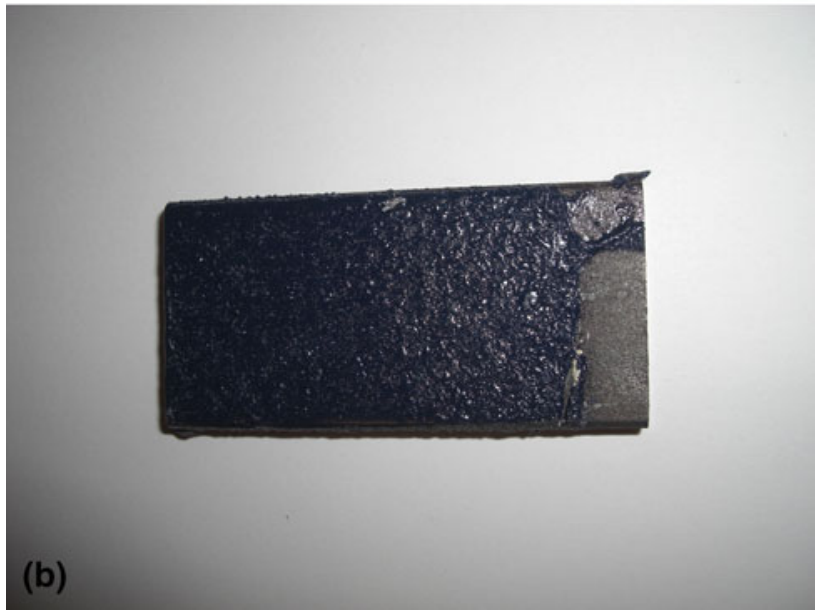

Fig. 3 (a) Porous coating obtained with stream-shaped nozzle, and (b) dense coating obtained with the cone-shaped nozzle
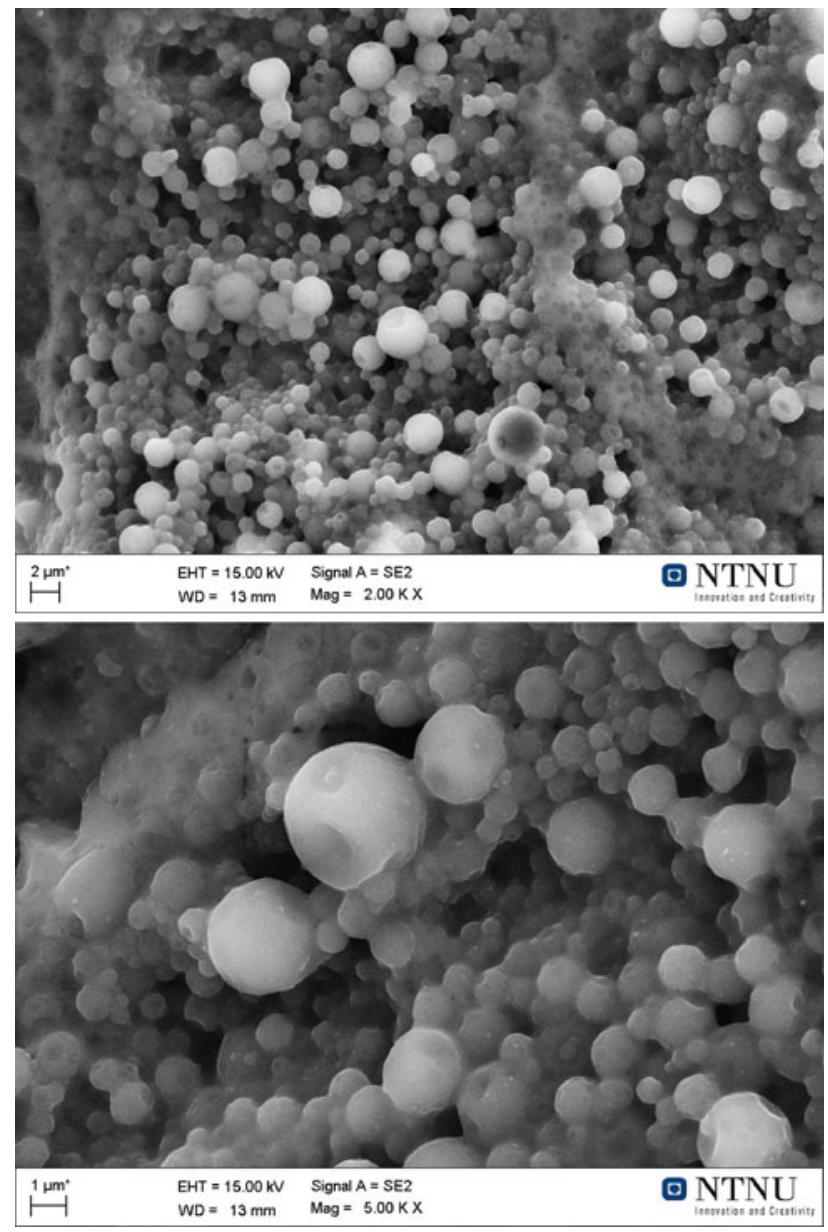

Fig. 4 (a) SEM image of the free surface of the as-sprayed capsules without matrix, and (b) as-sprayed capsules without matrix showing some deformation and coalescence after the spraying process

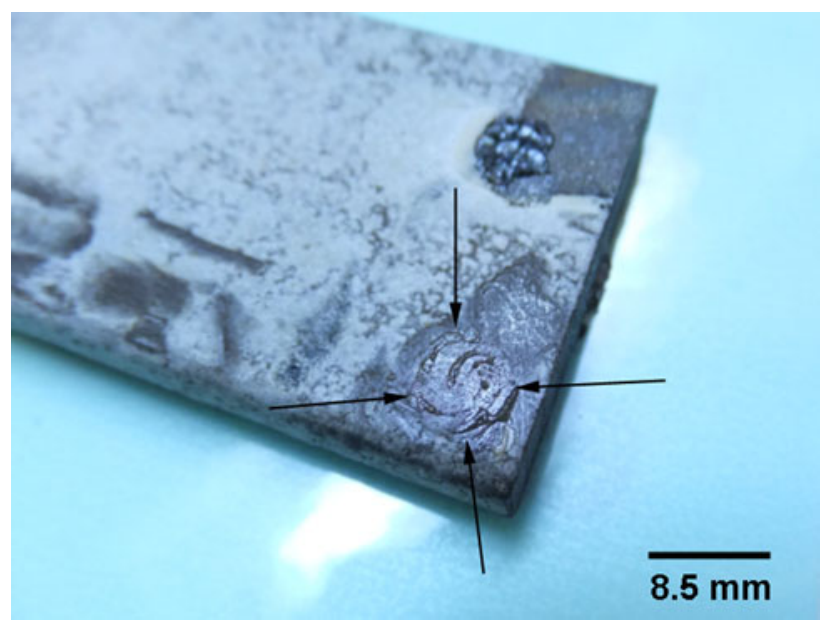

Fig. 5 Liquid is released after applying some damage to the coatings. The arrows point at the lubricant released after the damage 
ples presented in this study correspond to the typical parameters found for Nylon. The gases used for spraying the nylon were propylene and compressed air. The
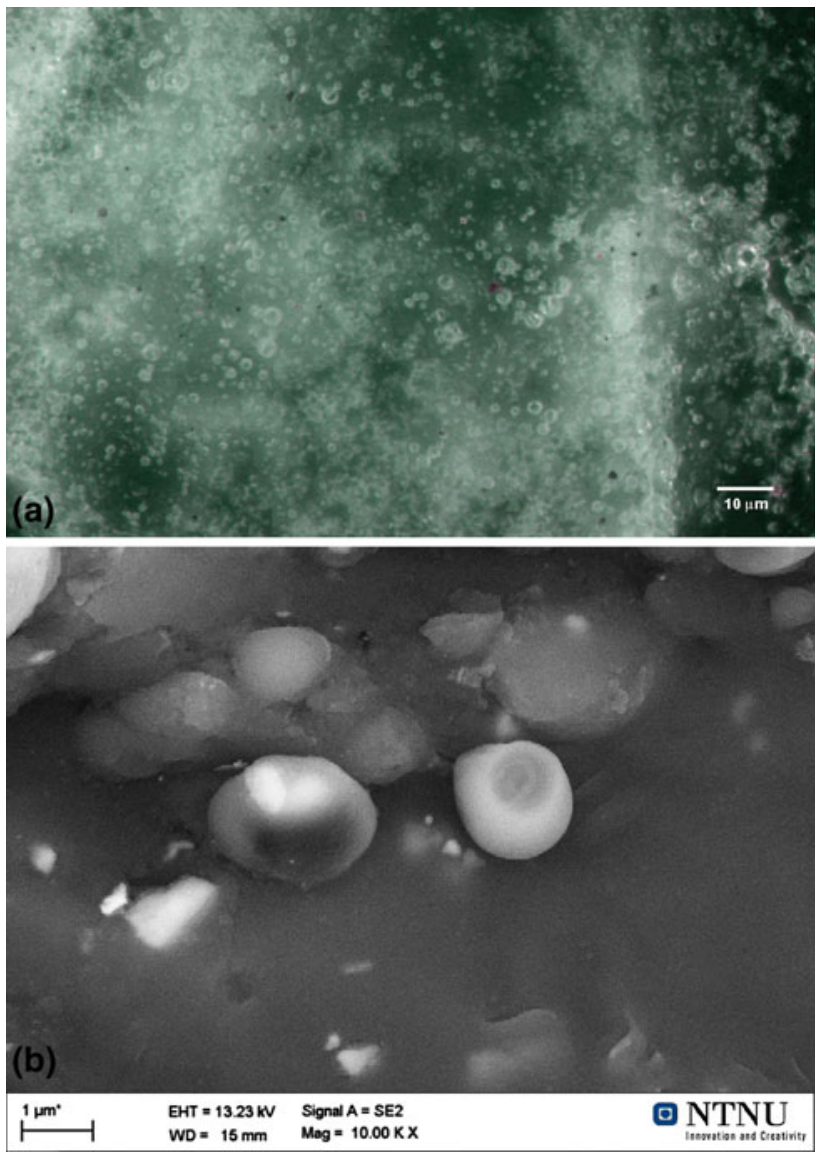

Fig. 6 Surface of the coating containing the capsules. (a) Optical image showing the distribution over the surface, and (b) SEM image showing a magnification of one single capsule

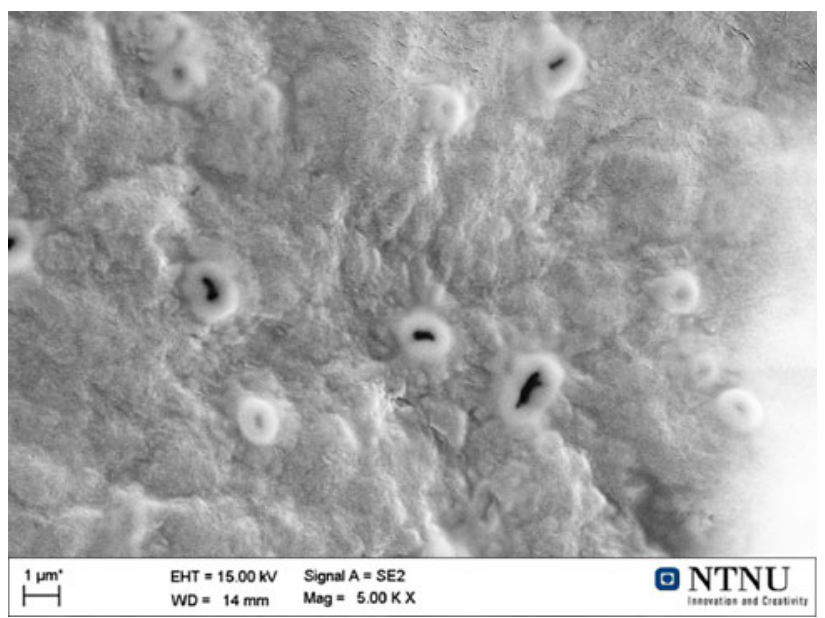

Fig. 7 Cross section of the polymeric liquid-solid coating showing the holes left by the capsules after polishing spraying distance was kept constant between 150 and $250 \mathrm{~mm}$, and air was used as carrier gas. The co-spraying of the capsules does not have an influence on the spraying parameters of the matrix. This enlarges the flexibility for producing coatings with different matrices and materials.

The nylon powder was fed into the flame-spraying gun in a conventional way (axial injection), while the capsules were introduced radially inside the flame using an independent powder feeder. The capsules were injected in a water-based solution with the aim at protecting the capsules from the high temperatures of the flame. The amount of the capsules injected inside the flame was controlled using a carrier gas (air).

The injection of the capsules was also varied by selecting different nozzles in the spraying system. It was observed that the nozzle played a very important role in the process and it also affected the coating properties. Based on different experiences and visual inspection, it was concluded that a cone-shaped nozzle gave the best results. The influence of the nozzle is clearly seen in Fig. 3, where the porous coating was obtained upon injecting the capsules with a cone-shaped stream, and the nonporous coating was obtained with the cone-shaped nozzle. It is also possible to observe how the capsules are not homogenously distributed with the cone-shaped stream. Therefore, the cone-shaped nozzle was used for producing the coatings containing liquid-filled capsules presented in this study.

3.2.2 Coating Produced Only with Capsules. This coating was produced to confirm the spraying performance of the liquid-filled capsules. In this particular case, the flame spraying gun was not fed with nylon, and only the capsules in the water-based solution were injected in the flame. The entire liquid was evaporated during the spraying process, and no evidence of water was found in the coatings.

The surface topography of the coating is shown in Fig. 4. This figure confirms that the capsules have the same shape and size as the original ones before spraying (Fig. 2). Few capsules were deformed plastically, and some coalesced during the thermal spray process as seen in Fig. 4(b). However, the microstructure of the coating reveals good cohesion and adhesion between the capsules.

Table 4 Average coefficient of friction (CoF) for a layer consisted solely of capsules, a pure nylon coating, and capsule-containing coatings

\begin{tabular}{lccc}
\hline Coatings & $\begin{array}{c}\text { Normal } \\
\text { load, } \mathbf{N}\end{array}$ & $\begin{array}{c}\text { Average } \\
\text { CoF }\end{array}$ & $\begin{array}{c}\text { Length of } \\
\text { the test, min }\end{array}$ \\
\hline Capsules layer & 5 & 0.16 & 10 \\
Nylon coating & 10 & 0.16 & 10 \\
& 5 & 0.47 & 30 \\
Capsule-containing coating & 10 & 0.47 & 30 \\
$\quad 5$ & 0.19 & 30 \\
Capsule-containing coating & 10 & 0.17 & 30 \\
$\quad$ (50\% PAO capsules) & 5 & 0.14 & 30 \\
Capsule-containing coating & 10 & 0.14 & 30 \\
$\quad$ (70\% PAO capsules) & 5 & 0.12 & 30 \\
\hline
\end{tabular}


A very simple scratch test done manually showed the release of liquid lubricant as shown in Fig. 5. This test confirms that the lubricant is still available inside the capsules, and it is easy to release when the capsules are damaged at very low loads.

\subsubsection{Nylon Coating Containing Liquid-Filled Polyurea} Capsules. These coatings consisted of a Nylon-11 matrix containing the lubricant-filled capsules. The Nylon-11 powder had a particle size $>100 \mu \mathrm{m}$.

The capsules and the nylon powder were co-sprayed, although the feeding system was different for each material to avoid a high thermal input into the capsules. The

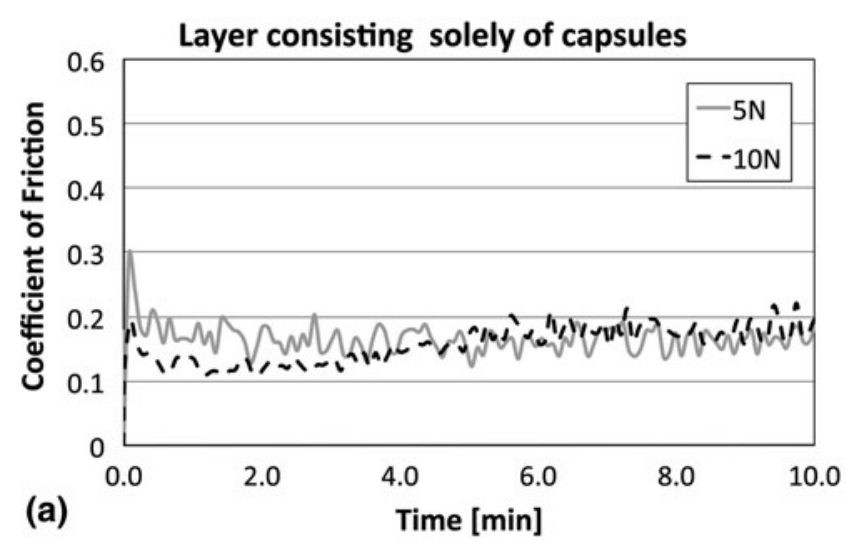

Capsule-containing coating (30\% PAO)

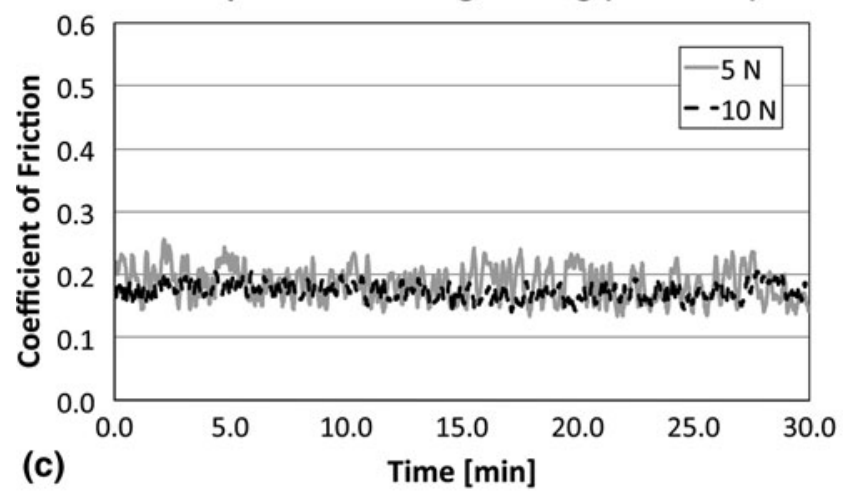

Capsule-containing coating (70\% PAO)

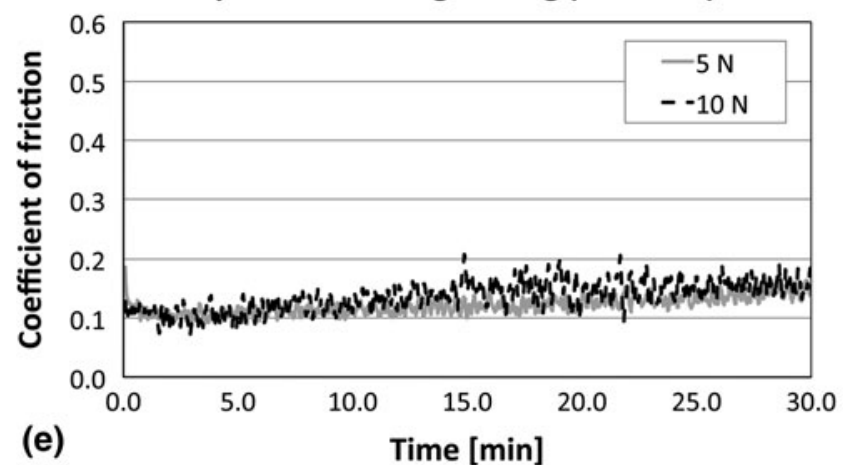

nylon powder was fed axially in the combustion chamber of the gun, whereas the capsules were fed externally and close to the nozzle with an independently controlled injecting system, which allows injecting the aqueous suspension inside the flame. The objective of the co-spraying process was to obtain a homogeneous distribution of the capsules inside the nylon matrix. The feeding rate of the capsules was adjusted to avoid any excess of liquid containing the capsules during the spraying process, which could enhance the pores formation in the coating.

The optical image in Fig. 6 shows a homogeneous dispersion of the capsules on the surface of the coating. These

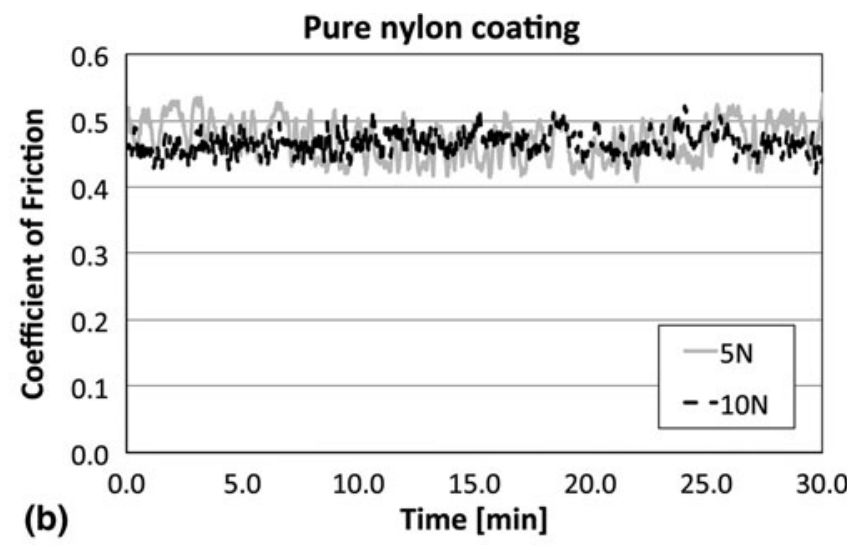

Capsule-containing coating (50\% PAO)

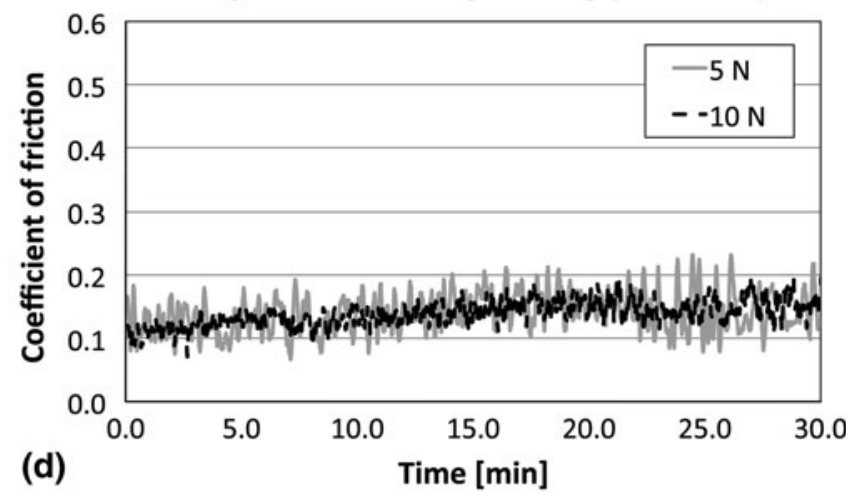

Fig. 8 Evolution of the coefficient of friction measured during 5 and $10 \mathrm{~N}$ for (a) a layer consisting solely of capsules, (b) a pure nylon coating, (c) a capsule-containing coating (30\% PAO), (d) a capsule-containing coating (50\% PAO), and (e) a capsule-containing coating $(70 \%$ PAO) 
particles on the surface are not covered by nylon because the nylon powder feeder was stopped before the capsules feeder.

The cross section of the coatings was analysed for confirming the presence of the liquid-filled capsules in the nylon coating. Figure 7 shows that the capsules inside the coating survived the thermal spray process. The cross section in Fig. 7 was obtained by cutting the coating in a $\mathrm{V}$-shape using a scalpel. The shape and size of the capsules was similar to the starting material and were well distributed in the matrix. This will allow controlling the mechanical and tribological properties of the coating.

\subsection{Friction Tests}

Friction tests of layers containing solely capsules, pure nylon coatings, and capsule-containing coatings were carried out to characterize the lubricating effect of the capsules. Please note that the coatings containing solely capsules were tested only for $10 \mathrm{~min}$ because of the poor mechanical properties due to the absence of the polymeric matrix. The other types of the coatings (all with polymeric matrix) were tested for $30 \mathrm{~min}$. The evolution of the CoF with time is shown in Fig. 8, and Table 4 gives the average value of $\mathrm{CoF}$ and the wear rate. The layer containing only capsules (Fig. 8) gave an average $\mathrm{CoF}$ of 0.16 for both normal loads of 5 and $10 \mathrm{~N}$. Coatings composed only of Nylon gave a $\mathrm{CoF}$ of 0.47 , while the introduction of capsules in the Nylon matrix reduced the $\mathrm{CoF}$ down to values between 0.12 and 0.19 for PAO-containing capsules. Three different capsules containing different amounts $(30,50$, and $70 \%)$ of PAO lubricant were used for producing the coatings. The CoF varied depending on the amount of lubricant in the capsules (Table 4).

These tribological tests show the lubricating effect of the liquid-containing capsules compared to a Nylon coating without liquid-filled capsules. Therefore, the capsules reduced the friction without affecting the mechanical properties of the coatings. The $\mathrm{CoF}$ was reduced because

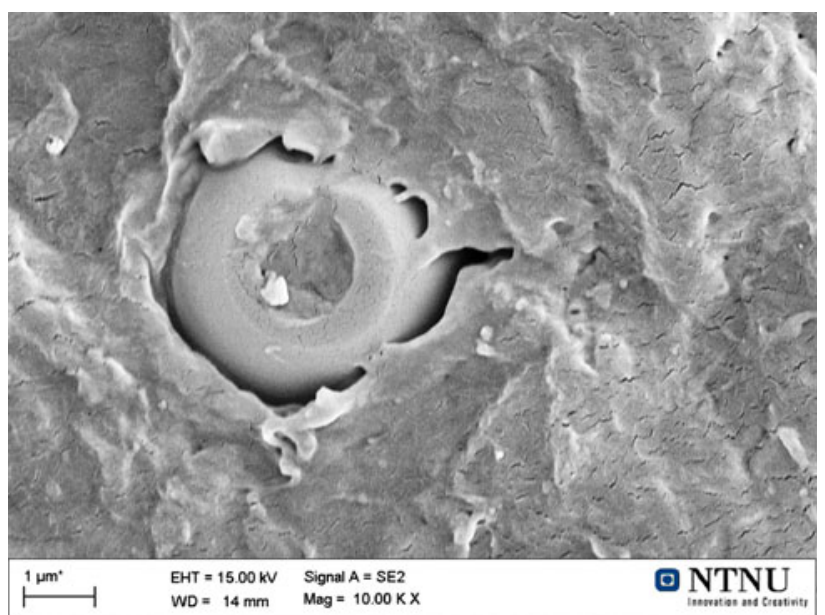

Fig. 9 Worn out capsule inside the wear track. The lubricant inside the capsule has been released, and the empty space has been filled with nylon debris of the release of the lubricant into the contact. Besides, the capsules showed good adhesion with the coating matrix; therefore, it was not possible to detach the capsules from the coatings without damaging them (Fig. 9). The reciprocating movement of the steel ball on top of the capsules wears out the external wall of the capsules, thus the lubricant was released to the system. Figure 9 shows a capsule that has been worn out. Inside the capsule, only debris coming from the nylon can be seen as the lubricant has been released.

\section{Conclusions}

The present study has shown the first liquid-solid lubricant coating obtained by thermal spray. The capsules used in the process were tailored to fulfil and withstand the harsh conditions of the thermal spray process (high temperature and large impact forces of the particles on the substrate). The following conclusions can be drawn:

- Polyalphaolefin (PAO) and silicone oil lubricants were used to produce liquid-filled polyurea (PU) capsules with average diameter in the range of 2-7 $\mu \mathrm{m}$. The production process for manufacturing the capsules can be modified for producing capsules made of different materials and sizes. The liquid contained in the capsules can be selected depending on the selfhealing properties required in the coating.

- The capsules containing PAO were sprayed with flame spray with and without polymeric feedstock material for producing liquid-solid coatings. The thermal spray parameters selected for obtaining the liquid-solid coatings were independent of the capsules. Depending on the thermal spray parameters, the capsules need to be injected in different positions or quantities. This shows that different thermal spray matrices can be used for producing self-lubricated coatings, opening a wide range of applications for these new liquid-solid coatings.

- The microstructural analysis of the coatings and the tribological tests performed showed that the capsules survived the thermal spray process conditions (temperature and impact forces).

- The lubricant inside the capsules was released during the sliding tests whenever the capsules were worn out, modifying the CoF depending on the amount of lubricant contained in the capsules. The coefficient of friction was reduced from 0.5 (coatings without capsules) to 0.15 (coatings containing lubricant-filled capsules). These low values of friction show the possibility of reaching boundary and mixed lubrication regimes in mechanical systems.

- This new family of coatings opens new possibilities for using thermal spray not only for producing selflubricating coatings but also for producing coatings with other self-healing properties (i.e., restoring integrity (Ref 1), corrosion resistance (Ref 14)) depending on the encapsulated liquid. 


\section{Acknowledgments}

The authors would like to thank the SINTEF Materials and Chemistry for funding this study through the internal project LiSoCo. The authors also like to thank Carlos Vaquero (Tecnalia, Spain) for producing the coatings and for his advice for developing the capsule-feeding system.

\section{References}

1. S.R. White, N.R. Sottos, P.H. Geubelle, J.S. Moore, M.R. Kessler, S.R. Sriram, E.N. Brown, and S. Viswanathan, Autonomic Healing of Polymer Composites, Nature, 2001, 409, p 794-797

2. R.P. Wool, Self healing Materials: A Review, Soft Matter, 2008, 4, p 400-418

3. M.R. Kessler, Self-Healing: A New Paradigm in Materials Design, Proc. Inst. Mech. Eng. G. J. Aerosp. Eng., 2007, 221(4), p 479-495

4. A.E. Hughes, I.S. Cole, T.H. Muster, and R.J. Varley, Designing Green, Self-Healing Coatings for Metal Protection, NPG Asia Mater., 2010, 2, p 143-151

5. B.E. Koene, S. Own, and R.S. Taushanoff, Self Healing Superhydrophobic coatings for corrosion protection, Department of Defense Corrosion Conference August 10-14, 2009
6. A. Kumar, L.D. Stephenson, and J.N. Murray, Self Healing Coatings for Steel, Prog. Org. Coat., 2006, 55, p 244-253

7. S.D. Siegmann, O.C. Brandt, and N.M. Margadan, Tribological Requirements of Thermally Sprayed Coatings for Wear Resistant Applications. Proc. 1st International Thermal Spray Conference -Thermal Spray: Surface Engineering via Applied Research, 2000, p 1135-1140

8. M. Erne, D. Kolar, C. Hübsch, M. Möhwald, and F.-W. Bach, Synthesis of Tribologically Favorable Coatings for Hot Extrusion Tools by Suspension Plasma Spraying, J. Thermal Spray Technol., 2012, 21(3-4), p 668-675

9. Maintenance and OSH-A statistical picture. Report from the European Agency for Saftety and Health at Work. http:// osha.europa.eu/en/publications/factsheets/90

10. J. Ugelstad, M.S. El-Aasser, and J.W. Vanderhoff, Emulsion polymerization: Initiation of polymerization in monomer droplets, J. Polym. Sci. C Polym. Lett., 1973, 11(8), p 503-513

11. M. El-Aasser and D. Sudol, Miniemulsions: Overview of Research and Applications, JCT Res., 2004, 1, p 21-31

12. J.M. Asua, Miniemulsion Polymerization, Prog. Polym. Sci., 2002, 27, p 1283-1346

13. K. Landfester, Synthesis of colloidal particles in miniemulsions, Annu. Rev. Mater. Res., 2006, 36, p 231-279

14. M.L. Zheludkevich, D.G. Shchukin, K.A. Yasakau, H. Möhwald, and M.G.S. Ferreira, Active Corrosion Protection Based on Nanocontainers with Corrosion Inhibitors, Chem. Mater., 2006, 19, p 402-411 